\title{
Exploring Food Decision Processes of Latino Families in California's Central Valley
}

\author{
Mirna Troncoso Sawyer ${ }^{1}$, Nelida Duran ${ }^{1}$, and Steven P. Wallace ${ }^{2}$ \\ ${ }^{1}$ California State University, Northridge \\ ${ }^{2}$ University of California Los Angeles
}

\begin{abstract}
Background and Purpose: Latino children are more likely to be overweight than non-Latino whites. Family food context research is relevant to the prevention of overweight. The purpose of the study was to identify patterns in Latino family food decisions related to the dinner routine. Methods: In 2013-2014, thirty-four in-depth interviews were conducted with twenty-two Latina mothers with children age 5-10 in California’s Central Valley. Previously published research informed the semi-structured interview guide. A grounded theory methodology was used to identify themes. Results: Four salient food decision approaches emerged. Families exhibited six combinations of these approaches. Mothers' explicit health goals guide the health approach. The traditional approach emphasizes eating favorite recipes. In the developmental approach, parents modify the main meal for children based on the belief children will develop an adult's taste over time. The path of least resistance favors expediency over other concerns. Conclusion: While the path of least resistance and health approaches have previously been observed among other populations, this paper provides findings on these categories among Latinos. Additionally, our findings on the developmental and traditional approaches expand the body of knowledge on food decisions. The guiding approaches provide a framework that can be sensitive to diverse food schemas.

(c) 2019 Californian Journal of Health Promotion. All rights reserved.

Keywords: dietary behavior; nutrition; Hispanic/Latino Americans; family characteristics; malnutrition; healthy diet
\end{abstract}

\section{Introduction}

Latino food behaviors have been studied extensively from the perspective of acculturation, or how the adoption of United States (U.S.) norms influence health. Previous literature has documented a loss of the family dinner routine by Latina immigrant mothers living in the U.S. (Lindsay, Greaney, \& Peterson, 2008; Lindsay, Sussner, Greaney, \& Peterson, 2009). It is unclear, however, what has led to the decline in the routine. Other research has identified the practice of feeding children alternative meals rather than the regular family meal (Kerber, Kessler, Wallace, \& Burns-Whitmore, 2014); allowing children to decide what they will eat inside and outside of the home, often permitting children to make less healthy choices (Turner, 2014); or permitting children to eat at different times from their parents, often while watching TV (Lindsay et al., 2009). In contrast, other research finds
Latino parents participating in healthy food behaviors and thus positively influencing their children. One study found immigrant Latino families were willing to spend extra money on vegetables if they knew their children liked them (Lindsay, Prelip, Kinsler, Toller Erasquin, Thai, \& Neumann, 2009) and another found Latino parents who ate more vegetables also seemed to feed their children more vegetables (Slusser, Toller Erasquin, Prelip, Fischer, Cumberland, Frankel, \& Neumann, 2011). However, we know little about how Latinos, especially immigrants, perceive the choices they are making about family meals and the decision-making schemas that lead to these food behaviors.

In contrast, research on food schemas among other populations has highlighted a deeper understanding of behavior. In a sample of low- to moderate-income white women living in a rural 
area, Blake and Bisogni (2003) provide an understanding of the cognitive processes involved in food choices. They identified four family food choice schemas: peacekeeper, healthy provider, struggler, and partnership. The peacekeepers accommodated the preferences and demands of as many family members as possible, often regardless of their own preferences or needs. Healthy providers focused on the health benefits and consequences of foods when they explained how they fed their families. They believed the foods provided influenced the current health of their family members and would establish healthful eating habits for later life. The strugglers were primarily concerned with obtaining a sufficient quantity of food and had feelings of inadequacy and an inability to deal with food preparation and budgeting financial resources. Those in the partnership category were primarily concerned with the fair distribution of family food choice activities, felt responsible for food-related activities, experienced limited enjoyment of cooking, and preferred to have others cook. Food schema research, pointing to food meanings and behavioral scripts, provides one framework for understanding the cognitive processes and food choice patterns within the family context.

While much is still unclear about Latino family food choice processes, research on the food choices of Puerto Rican girls highlights the role of cultural and structural characteristics in shaping food choices (Bowen \& Devine, 2011). Bowen and Devine (2011) in their study of acculturation, migration, and food choice among mainland and island-living Puerto Rican adolescent girls found food contexts differed for girls depending on three domains: experiences (migration experience, food preferences and values, and cooking skills), household context (composition, presence of a Puerto Rican grandmother), and their mothers (cultural orientation, health, work, and cooking skills). Given the three domains, the girls could be characterized as falling into four food choice types: everybody cooks, tradition keeper, seeker, and on my own. This research shows that food selection is influenced by social and physical contexts, which might vary to a great extent among immigrant populations who have a variety of migratory and household structures, such as Puerto Ricans. The context of migration and household structure might also be relevant for other populations of Latinos, in addition to the process of acculturation, or adoption of cultural norms, as identified in the current literature.

Little to no research on food choice processes has been conducted among immigrant Latinos in rural California. The plethora of research on certain food behaviors among Latino families lacks a framework that explains how or why different families make health-promoting food decisions. More research is needed to understand the diversity of food schemas among Latino families.

The following paper is based on findings from a larger socioecological investigation designed to explore the food decisions of Latino families within the context of workplaces, schools, and family life in a rural, agricultural California community (Sawyer, 2015). The typology of family food schemas described by this paper explains the interaction among culture, structural characteristics, and food context among the Latino families studied in rural California.

\section{Methods}

\section{Study Design}

To understand the food and daily context of families, in-depth interviews were conducted. Qualitative methods were informed by a grounded theory approach to ethnographic research (Charmaz, 2006). IRB approval was obtained from the University of California at Los Angeles. Written consent was obtained from participants prior to their interviews.

\section{Sample}

A convenience sample of twenty-two mothers with children were recruited through a charter school in California's Central Valley. The eligibility requirement was to be a mother of a child attending the target school in grades kindergarten through third grade. The school gave families 10 hours of volunteer credit for participating in the study. The volunteer credit was a strong incentive as families were required to serve 30 hours of volunteer work at the school 
during the school year. Mothers were recruited through in-personal oral presentations made by the first author during school health forums and parent cooking classes and by one-on-one recruitment in booths during days set aside for parent-teacher conferences.

\section{Measures}

A semi-structured interview guide (Table 1) was constructed using items from a study conducted by Blake et al. (2013) and informed by the Food Choice Process Model (Sobal and Bisogni, 2009; Furst, Connors, Bisogni, Sobal, and Falk, 1996) and the Life Course Model of Food Choice (Devine, 2005), as well as developed by the research team. These models propose that experiences throughout the life course influence ideals, personal factors, resources, social framework, and food context and these factors may influence each other and the personal system. The personal system refers to one of the main factors that impacts food choice and includes conscious value negotiations and unconsciously operationalized strategies that may occur in food-related choice situations (Furst et al, 1996.) The personal system shapes values associated with sensory perception, monetary considerations, convenience, health and nutrition, managing relationships and quality which ultimately inform strategies related to food choice.

\section{Table 1.}

Interview Questions

1. Is everyone present at dinnertime?

2. Do you have a dinnertime established in your family?

3. Can you describe the foods that you usually eat? Give me an example of a typical day. Are all the days the same? Probes: days off work, weekends, holidays, seasons.*

4. How often do you try to incorporate new dishes/meals?

5. How often do you buy cookies, chips, etc.?

6. Which vegetables do you tend to incorporate in your dishes?

7. What time do you start making dinner?

8. Tell me about a typical dinner. Who prepares it? Who decides what will be served? What are these decisions based on? Probes: preferences of others in the household, self preference, health considerations. (Whose?) *

9. At what age did you begin to cook for yourself or for your family?

10. How does the way you eat compare with others that you know? In your family? Coworkers? Someone from another place? What about your kids? Do they eat the same thing as you? The same as each other? (If she says not the same, ask why and ask for examples.)*

11. What are the preferred drinks in your household?

12. Where do you usually eat? If at home, where else do you eat besides home?*

13. When you eat at do you choose foods differently than you might at home? Probes: When you eat at home versus when you eat at someone else's house or a restaurant? What kinds of foods? How do you decide on what foods to choose in these different types of situations?*

* Denotes questions adapted from previous studies.

\section{Data Collection}

The first author who is bilingual in English and Spanish conducted all data collection. She was trained in qualitative research methods in her graduate course work. Data were collected between February 2013 and April 2014 and consisted of 34 in-depth interviews with 22 women. Nine out of 22 women completed

follow up interviews, which were needed to further examine themes that emerged from the initial interview. The average length of the initial interview was 45 minutes. The length of follow- 
up interviews ranged from 15-45 minutes. Twelve participants conducted their interviews alone at the recruitment site or at their home and the other ten respondents had interviews in their homes while children and/or husbands were present. Interviews were conducted in English or Spanish depending on participant preference. Interviews were audio recorded and transcribed. Follow-up interviews were conducted on topics that were explicit in some interviews and remained implicit or absent in others. The emphasis on understanding the behavior of study participants is to reveal multiple layers of meanings to their actions (Charmaz, 2006). Following Kathy Charmaz's (2006) guide to grounded theory research, investigators aimed to uncover five layers of meaning: (1) participant's stated explanation of his or her action, (2) any unstated assumptions, (3) intentions for engagement, (4) its effect on others, and (5) consequences for further individual action and interpersonal relations.

\section{Data Analyses}

The first author conducted coding of all transcripts with additional coding on two transcripts by the third author. Data collection and analyses were conducted simultaneously.

The emerging data were studied observation-byobservation and interview-by-interview, although some interviews were conducted before the completion of data analysis from the previous interview. Investigators used the "open coding" method (Berg, 2001) rather than line-by-line coding. The open coding method allowed for the systematic identification and extraction of themes, topics, or issues. Following the creation of an initial set of theoretical categories using open coding, categories were refined using a focused coding method. Focused coding refers to taking earlier codes that reappear continuously during initial coding and using those codes to sift through large amounts of data (Emerson, 2001). Focused coding allowed researchers to create and test categories for capturing and analyzing data.

Key concepts for examining participants' cognitive constructions of the dinner routine were formulated and delineated using an iterative process of reviewing the literature and analyzing emergent themes from the data.

\section{Results}

Eleven of the mothers who participated in this study were born in Mexico and immigrated to the U.S. as adults; four immigrated to the U.S. before the age of sixteen years. Seven are second or third generation U.S citizens who grew up in lowincome communities in the Central Valley. Table 2 provides additional information about participants. In all of the families who participated in the study, mothers are primarily or completely in charge of preparing, cooking, and serving meals. From the perspective of these mothers, a set of food meanings (self-reported beliefs) and behavioral scripts (behavioral plans for regularized food and eating situations) emerge as salient. Family members often eat breakfast and lunch separately. Children eat lunch at school where food choices are institutionally determined (only one of the families in this study makes lunch for their child) while dinner is often eaten together, or at least in the home, and reflects family food decisions. Four different approaches to family food decisions at dinner were identified: health, traditional, developmental, and a path of least resistance. While these four are the general guiding approaches, families exhibited six combinations (Table 3) of these approaches. These include health for parents and path of least resistance for children, health for both, health for parents and traditional for children, traditional for parents and developmental for children, traditional for both, traditional for parents, and path of least resistance for children.

Table 4 provides a list of the guiding approaches, organizing principles for each, examples of food decisions per category, and example quotes from different families in each category. Thirteen of the 22 families in the study primarily follow the same guiding approach to food decisions while the other nine parents and children display different guiding approaches. 
Table 2.

Participant Demographic Characteristics ( $\mathrm{n}=22$ )

\begin{tabular}{llllllll} 
Participant & Age & Nativity & $\begin{array}{l}\text { Educational } \\
\text { Attainment }\end{array}$ & $\begin{array}{l}\text { Marital } \\
\text { Status }\end{array}$ & Children & Work Status & Work Industry \\
\hline 1 & 28 & US & CC Student & Married & 5 & Stay-at home & Homemaker \\
2 & 33 & US & CC Student & Married & 4 & Stay-at home & Homemaker \\
3 & 39 & Mexico & 6th Grade & Married & 2 & Stay-at home & Homemaker \\
4 & 42 & Mexico & 7-9th Grade & Married & 5 & Stay-at home & Homemaker \\
5 & 36 & Mexico & 5th Grade & Married & 3 & Stay-at home & Homemaker \\
6 & 29 & US & CC Student & Married & 4 & Stay-at home & Homemaker \\
7 & 34 & US & HS Graduate & Married & 5 & Stay-at home & Homemaker \\
8 & 40 & Mexico & 6th Grade & Married & 3 & Stay-at home & Homemaker \\
9 & 31 & Mexico & Some College & Married & 4 & Stay-at home & Homemaker \\
10 & 47 & Mexico & 6th Grade & Married & 5 & Stay-at home & Homemaker \\
11 & 48 & Mexico & 6th Grade & Married & 2 & Part-time & Housekeeping \\
12 & 32 & Mexico & CC Student & Married & 3 & Regular & Food Worker \\
13 & 27 & US & College Student & Married & 1 & Regular & Park Guide \\
14 & 28 & Mexico & CC Student & Married & 4 & Regular & Office Work \\
15 & 21 & Mexico & 11th Grade & Married & 3 & Regular & Office Work \\
16 & 31 & US & College Graduate & Married & 4 & Regular & Daycare Center \\
17 & 34 & Mexico & College Graduate & Married & 2 & Regular & Teacher \\
18 & 27 & Mexico & 6th Grade & Married & 1 & Regular & Farm Worker \\
19 & 55 & Mexico & 11th Grade & Married & 3 & Nonstandard & Factory Work \\
20 & 32 & Mexico & 11th Grade & Married & 3 & Regular & Farm Worker \\
21 & 35 & Mexico & CC Student & Married & 2 & Regular & Daycare \\
22 & 31 & US & College Graduate & Married & 4 & Nonstandard & Factory Work \\
\hline
\end{tabular}

$\mathrm{CC}=$ Community College

Table 3.

Primary Family Food Guiding Approach

\begin{tabular}{lc}
\hline Approach & \# of Families \\
\hline Traditional & 7 \\
Health & 6 \\
Health (Parent) + Path of Least Resistance (Children) & 3 \\
Health (Parent) + Traditional (Children) & 1 \\
Traditional (Parent) + Developmental (Children) & 1 \\
Traditional (Parent) + Path of Least Resistance (Children) & 4 \\
Total & 22 \\
\hline
\end{tabular}


Table 4.

Sample Quotes Supporting the Primary Family Food Guiding Approaches (n=22 families)

\begin{tabular}{lll}
\hline Approach & $\begin{array}{l}\text { Organizing } \\
\text { Principles }\end{array}$ & Examples of Food Decisions \\
\hline & Implement health & Salad or vegetables with dinner, \\
goals; spectrum of & lunch, for snack; reducing soft \\
goals; time of & drink intake; limiting or avoiding \\
implementation may & fast food intake; avoiding snack \\
& vary & foods; frying only once a week; \\
& & buying fast food at Subway \\
& &
\end{tabular}

Consume meals Traditional Mexican (flautas, traditional to family; for immigrant families these are traditional Latino dishes

"Scaffold" children's palate with versions of main meals

Expediency; reduce family friction; give child preferred foods

albondigas, enchiladas, tacos, posole, menudo, lentejas, coctel de camaron, frijoles, arroz, carne asada, milanesa, salsa, tortillas); traditional to family (recipes passed on from parents/friends, fried chicken, mashed potatoes, spaghetti, breaded chicken steak (with store bought bread crumbs, milk, egg, pepper), potato, carrots, broccoli

Traditional Mexican but younger children are made alternatives, for example, instead of full chile relleno egg batter fried and served with tomato sauce without chili

Quick meals like Cup-o-Noodles, sandwich, burrito, frozen items like Hot Pockets, fast food like pizza, McDonald's

\section{Example quotes}

"We do both read a lot of articles about health and things like that. And it was kind of a gradual thing I would say;" "I see the shopping carts full of processed food. Now I am making more money than I used to make and I can afford that stuff but I don't need that, they don't need that. They don't need the fast food, they don't need the junk food."
"Well when one likes to, my mom used to say, and it was always my mom, my mom would say. [She would say] she was going to teach me but she didn't like to teach so [she said] remember, just watch the way I do it so you can learn, and that's how I learned. My husband likes what I make, the sauces I make for the enchiladas, he doesn't like me to buy [the premade kind]."

"What I do sometimes is that with the egg that is leftover I take some of it and I put the tomato sauce on top. Because what I do is with the leftover rice from the chilies, I tear the tortilla into small pieces and I fry it with a little bit of oil. And since they don't like chili, well I make that for them."

"Typically I make something for my husband and I make something else for my kids. My daughter is the pickiest, according to her she does not like chicken but she eats chicken nuggets at Denny's. She also says she doesn't like beans but when I make enfrijoladas the kids eat them. So that's why I make things that they will eat;" "I'm not going to lie to you because when one is working it is the easiest thing to do..." 


\section{A Health Approach}

Food decisions guided by health attempt to achieve an explicit health goal through changes in diet or by promoting food decisions for health reasons. In about a quarter of the families in this study, health is the major concern (food meaning) when planning meals (behavioral scripts) and a majority of food choices are driven by what families believe makes different foods "healthier."

Families in this category might reduce beef intake, substitute lower fat milk for higher fat milk, or include salads with dinner because they believe those choices promote health. This category includes U.S. born mothers, mothers born in Mexico, stay-at-home mothers (homemaker), and mothers with regular work hours. Of note, however, all mothers in this category had at least attained a high school education.

The following case is a respondent family in which both parents and their children follow a health approach. Amelia, who lives in a smallsize family home with peeling paint and a grassless front yard is 28 years old, energetic, and full of thoughts regarding her family's food behaviors. She has a daughter (2 years) and four sons (ages 1-12 years old). Amelia is a secondgeneration Mexican-American. Amelia's husband is 31 years old. Amelia is a stay-at-home mother who spends most hours of the day in household labor (i.e., cooking, cleaning, and caring for her children). With a large family, she explains, "food prepping” (a behavioral

plan) allows her to quickly cook pre-prepared vegetables along with marinated meats at dinnertime. She works on "food prep" in the morning and stores items in plastic bags until she makes dinner in the evening.

When the older children arrive from school, she and her husband take turns shuttling them around to after-school activities. Amelia attended community college for years, but now with five children, the prospect of returning to school seems unreachable, she says. Amelia and her husband have been interested in health for a long time and often read articles on the topic. They stopped eating fast food six months before their interview. She underscores this was a conscientious change in eating patterns, contrasting her current family's food choices with her mother's traditional Mexican cooking, "You know my mom [made] a lot of things I don't make. [She was not] conscious of protein, carbs, vegetables...my mom is just like carb carb carb and then let's throw in some carbs and sugar."

Amelia did not grow up eating a diet abundant in vegetables, but rather a diet she considers starchy and fatty. Now she is happy to accommodate her husband's food preferences. Still, for Amelia the change was gradual, "He's always enjoyed healthy food ... when I was growing up I [did not] enjoy healthy... So when we would go out to a restaurant I would order fries as my side. He would order vegetables and make me look like a fool." Their intentions for healthier family meals have grown over time. First, their consciousness was raised: "We do both read a lot of articles about health and things like that. And it was kind of a gradual thing I would say." They consumed a "juice fast" more than a year ago, and the feelings they experienced led to further selfreevaluation. "We felt just healthy. I can't put any other words to it. Healthy not sick. Not sleepy. Not lethargic. It just makes you feel good. It makes your skin wonderful. Lots of wonderful things with a juice fast. And we were like, 'ahhhhhh." Amelia's example highlights the myriad of behavioral plans families engage in to improve health such as trying a juice diet and/or eliminating fast food from their diet. Amelia and her husband's health preferences transfer to their children by way of the daily meal routine of including vegetables with dinner, vegetables as snacks during the day, and the elimination of fast food from the diet.

\section{A Traditional Approach}

Food decisions guided by tradition emphasize eating recipes passed down over generations or adopted as favorites (food meanings) and may require a great deal of preparation and/or quite a number of ingredients (behavioral plan). Common examples of foods passed down over the generations include carne con chile (beef chili stew), caldo de pollo (chicken soup), albondigas (meatball soup), and enchiladas (tortillas fried in 
chili sauce and stuffed with cheese or meat). When the family food schema is guided by tradition, there is an expectation that children will eat what is prepared. In seven of the 22 families in this study both parents and children follow a traditional guiding approach. In this group there were mothers born in the U.S. and Mexico. Table 4 provides more details about foods prepared in the traditional approach that are not traditional Mexican foods. The following section describes a respondent family with the schema in which both parents and children follow a traditional approach.

Carolina (48 years old) makes traditional food, and every day the family eats dinner together (behavioral plan). All members of the family appear overweight, except the adolescent son (12 years old) who is said to be a bit delicado (picky) about food. They eat mostly traditional food, use a lot of oil to fry, and put butter on vegetables; they opt for fried alternatives of otherwise healthier, less processed foods such as tostadas.

Carolina's cuisine requires a great deal of preparation and/or quite a number of ingredients (behavioral plan), as evidenced by a recipe she shared for Caldillo de Habas (Fava Bean Stew). When Carolina, like other immigrant participants, talks in-depth about traditional recipes, there is a sense of nostalgia apparent about how family recipes used to be passed down orally between the generations, or learned experientially.

While the foods Carolina prepares are traditionally Mexican, she and her family additionally purchase meals in local fast food outlets on occasion but not typically as part of their dinner routine. For example, on the weekend when they do their food shopping, especially when they shop in a large nearby city they will consume meals at food outlets, and also during the week when they purchase the youngest child McDonald's after school. Despite the integration of fast food into the family meal routine, Carolina happily boasts that her sons love traditional Oaxacan and Mexican cuisine. In the traditional approach, the emphasis is on foods made for generations that hold a particular meaning for the family.

\section{Combination Food Processes: A Developmental Approach}

In the developmental approach, parents prepare a variation of the traditional meal for children (behavioral plan) based on the belief children are not willing to eat the same foods as adults, but will develop a taste for adult foods over time (food meaning.) This approach is a variation of the traditional approach observed in one family with a Mexican immigrant mother with children who are less than 10 years of age. An additional family used this approach occasionally with two of their youngest children, but for the most part they leaned toward a traditional approach and therefore were categorized as traditional. Not always explicit, the goal underlying this approach appears to be a desire to incrementally expand children's palates to develop a taste for traditional dishes. That is, mothers prepare a traditional dish and then an alternative of the traditional dish with the goal of eventually transitioning the child to also eat the traditional dish (behavioral plan). The following case exemplifies food decisions guided by a developmental approach.

Nadine (28 years old), who as a child made trips to the U.S. every summer to harvest fruits and vegetables with her family, moved to the U.S. from Mexico when she was a teenager. She and her husband, Marco, (32 years old, works with machinery at an agricultural company) have been married for nine years and have three daughters (ages 1, 5, and 7 years) with another baby on the way. She used to wake up at five-thirty in the morning to make dinner so that eating between 4 p.m. to 5 p.m. only required reheating food. She works in a clerical position in a healthcare setting in a large nearby city. Her husband, a firstgeneration immigrant from Mexico, helps her serve dinner.

On a typical night in Nadine's home the children and parents eat similar foods with some variation. The kids sit down and begin eating dinner first and then the adults sit down (behavioral plan). When I asked why they do this, Marco said, "We serve them first. When they no longer ask for anything then we sit down...They also finish dinner first." For example, on one night, the children had caldo de fideo (tomato-based soup with vermicelli pasta and chicken broth) with 
tortillas while the parents had the same dish and calabacitas con queso (squash with cheese.) Marco mentions he did not always eat what his parents ate when he was growing up. Still, parents and children are eating some of the same foods (i.e. caldo de fideo). It is unclear whether children whose families follow a developmental approach will eventually eat all or the same versions of the foods their parents eat.

\section{Combination Food Processes: A Path of Least Resistance Approach}

The second most common guiding approach to meals that emerged as a combined approach was a path of least resistance. Food decisions guided by a path of least resistance allow family members to decide or influence his/her own meal (behavioral plan) and are based on the belief that obligating children to eat the same meal will cause conflict (food meaning). Conflicts of this type may be related to interpersonal relations, scheduling conflicts, time, and habit, among other factors not elaborated in this paper but explored more in depth elsewhere (Sawyer, 2015). These meals typically emphasize convenience and are often highly processed "fast food," packaged, processed, or frozen foods. Parents follow a separate guiding approach to their personal food decisions while their children's meals follow a path of least resistance approach. All of the mothers represented in this category were born in Mexico; however, the educational attainment level of the mothers' ranges from $5^{\text {th }}$ grade to some college. In three families, parents followed a health approach while children followed a path of least resistance approach. In four families, parents followed a traditional approach, while children's meals were aligned with a path of least resistance approach.

The following case exemplifies a model family in this category. Linda (35 years old), who emigrated to the U.S. from Mexico when she was a teenager, and her husband (38 years old), who came to the U.S. from Mexico as an adult, are in the home childcare business. They have two young children (5 and 6 years old) of their own who used to attend their childcare center. Recently, their children began elementary school. She describes how she decides what to prepare for dinner stating, "Typically I make something for my husband and I make something else for my kids." Then she discusses her daughter's pickiness stating: "She does not like chicken but she eats chicken nuggets at Denny's. She also says she doesn't like beans but when I make enfrijoladas [a torta sandwich filled with refried beans] the kids eat them. So that's why I make things that they will eat." When asked about what she and her husband eat, she responded, "Since we have been watching our weight it's salads with chicken. For tostadas I used to have cueritos and patas [pickled pigs' feet and skins,] not that anymore, just tostadas with beans and vegetables." Linda and her husband follow a health approach for their own meals.

Linda points out inconsistencies in her daughter's adamant refusal of beans and chicken even though she eats enfrijoladas and chicken nuggets. Linda does not obligate her children to at least try the foods they do not like (behavioral plans). Opting for the least resistance from her children, she prepares dishes they favor while she prepares low calorie dishes for herself and her husband. Linda expresses no expectation her children will eventually want the same foods she and her husband eat.

\section{Health and Other Combinations}

In one family the parents followed a health approach while children's meals were aligned with a traditional approach. In three families, parents followed a health approach while children's meals were prepared following a path of least resistance approach.

\section{Traditional and Other Combinations}

Four families had parents that follow a traditional approach whereas the children follow a path of least resistance approach. And in one family the parents follow a traditional approach while the children's meals follow a developmental approach (See the Developmental approach section above).

\section{Discussion}

This investigation was designed to gain a conceptual understanding of the meanings of the food choices of low-income Latina women and their families in rural California, a hard-to-reach 
population for which information about food choice is lacking. Qualitative research methods provided the opportunity to build on prior research and, by merging the perspectives from several fields of study with the perspectives of participants, their beliefs related to food choice could be better understood.

The guiding approaches advanced by this paper offer a greater understanding of the diversity of food schemas among Latinos. While two of the categories that emerged from this study have been observed previously in other populations, this research expands what is known about Latinos and provides a framework to organize a number of findings reported by other researchers. Food choice is dynamic in nature; therefore, even though we have reported the guiding approaches as a primary pattern for families, not all of them practice the same pattern every day. The four guiding approaches are health, traditional, developmental, and path of least resistance. While these four are the general guiding approaches, families exhibited six combinations of these approaches including health for parents and traditional for children, health for parents and path of least resistance for children, health for both, traditional for parents and developmental for children, traditional for both, traditional for parents and path of least resistance for children.

The health guiding approach in this study is related to the healthy provider schema (Blake \& Bisogni, 2003) and the nutritionist perspective (Kirk \& Gillespie, 1990) in other studies, which are characterized by health orientations among mothers and their families. In this study both recent immigrant and U.S. born Latina mothers enacted health-guiding family food approaches. This finding challenges the underlying assumption that beliefs or norms concerning particular behaviors change with overall acculturation or generation (Abraído-Lanza, Armbrister, Flórez, \& Aguirre, 2006), as well as the use of acculturation theories and linear models to explain Latino food behaviors (Mazur, Marquis, \& Jensen, 2003; Lara, Gamboa, Kahramanian, Morales, \& Hayes Bautista, 2005; Ayala, Baquero, Klinger, 2008; Batis, Hernandez-Barrera, Barquera, Rivera, \& Popkin, 2011). The fallacy is inherent in the idea that a health orientation can only develop after prolonged or with limited exposure to U.S. culture. A more nuanced perspective will avoid the approach of measuring proxies of culture as a way to predict health but instead will seek to identify the diversity of food behaviors to more thoroughly inform health promotion practice and research.

The traditional category, like the other categories, captures food decisions that are particular to that family. Families in the traditional category prepared foods passed down over generations, although some of those foods may not have been traditional Latino foods, such as "lemon pepper chicken.” The traditional category defined in this study is similar to the "tradition keeper" category identified in Bowen and Devine's (2011) study among Puerto Rican girls, which was defined by the girls practicing cultural food customs that had been passed on to them. The "tradition keepers" in Bowen and Devine's (2011) study primarily engaged in home cooking and had flexible work hours. Similarly, the Latina immigrant mothers who enacted the traditional approach in the current study were typically stay-at-home mothers. In contrast, U.S. born or 1.5 generation Latina mothers who enacted a traditional approach often worked outside of the home. A salient factor for moms who enacted the traditional approach is the desire to continue or establish certain traditions. Since culture inevitably changes, so do traditions, and thus the typology proposed by this study allows for a traditional category that is not based solely on nativity and allows for an expansion of the definition of traditional. A broader concept of what it means to eat traditional Latino food is important because Latino families are heterogeneous and often comprise parents with differing nativities.

The developmental approach, or the guiding principal to family meals that involves scaffolding children's food decisions by preparing a slightly modified version of the main meal, has not been identified in the literature of food schemas and perspectives. While only one family exhibited the developmental approach, the category was retained in the framework because recent research using the framework advanced by 
this paper has shown the pattern to be prominent (Sawyer, Duran, Luna, 2018; Duran, Sawyer, Luna, 2018.) Aimed at testing the relationship between family food decisions, teen food behaviors, weight status, and diet quality, ten percent of Latino teens in the pilot study $(n=83)$ identified their family food approach as developmental (Sawyer et al., 2018; Duran et al., 2018.) Nevertheless, a caveat is in order. In this study the developmental approach is based on one case. More research is needed to understand this food schema or guiding approach.

The path of least resistance approach has been termed the peacekeeper schema (Blake \& Bisogni, 2003) and the family diplomat (Kirk \& Gillespie, 1990) perspective in other studies. In both those cases and in ours, the food meaning behind the approach to food decisions is to reduce schisms among family members at mealtimes. Other studies have observed similar behaviors among parents and their children to avoid mealtime conflicts. For example, parents might stop offering new foods to their children when they exhibit a fear of the new food (Carruth \& Skinner, 2000; Carruth, Ziegler, Gordon, \& Barr, 2004) and this often leads to feeding children the same meals repeatedly. Studies have also found Latino parents feed their children alternative meals rather than the regular family meal (Kerber et al, 2008). Other studies find parents allow their children to decide what they will eat at home and outside of the home (Turner et al., 2014; Gomel \& Zamora, 2007) often allowing them to make less healthy choices. Finally, some Latino households no longer maintain a regular family dinner, but instead engage in individualized eating (Lindsay et al., 2009; Sussner et al, 2008). Individualized eating has been linked to risky health outcomes (Blake, Wethington, Farrell, Bisogni, \& Devine, 2011). The path of least resistance approach to food decisions represents one typology that includes these approaches among Latino family food decisions.

\section{Limitations}

One limitation of this study was its small sample of Latina women from one rural community in California's Central Valley. The specific types of family guiding approaches that emerged in the study might not be observed in the same way among other Latinos in urban areas or other regions of the country. Another challenge includes limited discussions with mothers about their personal guiding approaches. Although personal food decisions of the mothers were discussed in interviews and conversations, it was not explored in-depth. As mentioned by others (Blake \&Bisogni, 2003), linking the guiding approaches or food schemas of mothers and their family might elucidate how or why certain choices are made and thus provide insight about interventions in families who need support to adopt healthier food behaviors. More investigation into this aspect of food decisions may have contributed additional findings. Finally, given that families were enrolled in a charter school with healthy meal policies, gardens, and cooking classes, the study may not be generalizable to other Latinos.

\section{Study Implications and Conclusions}

Represented in the data were four family food choice schemas and six combinations of parental and child food schemas. Studies on Latinos and food attitudes often rely on acculturation metrics to explain variability (Mazur, Marquis, \& Jensen, 2003; Lara, Gamboa, Kahramanian, Morales, \& Hayes Bautista, 2005; Ayala, Baquero, Klinger, 2008; Batis, Hernandez-Barrera, Barquera, Rivera, \& Popkin, 2011) rather than seeking to identify the diversity of guiding approaches to family meals among Latinos. The typology set forth by this research highlights how Latinos, even those with low educational backgrounds or those who recently immigrated to the U.S., may demonstrate a strong concern for healthful eating. Alternatively, Latinos born in the U.S. or elsewhere may primarily be concerned with expediency in favor of a "path of least resistance" approach to food decisions.

Employing a qualitative research design helped investigators identify a typology of Latino family food guiding approaches. While food schemas and food perspectives (Kirk \& Gillespie, 1990) have previously been identified among some populations (Blake \& Bisogni, 2003), the current study expands the knowledge of these processes among Latinos. The findings advanced by this paper can be used in the development of a tool to assess the prevalence of diverse food schemas 
and to test the utility of this typology in promoting health. Understanding common cultural schemas contributes to program planning and message development (Blake \& Bisogni, 2003).

The categorization of the schema presented provides public health professionals the opportunity to develop educational strategies that are responsive to the participants' food guiding approaches. The high proportion of families exhibiting the traditional food guiding approach presents an excellent opportunity to introduce healthy adaptations of traditional recipes (e.g., replacing frying with baking) and greater adoption of healthy traditional foods (e.g., mixed fruit marinated in lime juice and sprinkled with TAJIN ${ }^{\circledR}$ seasoning), thus creating culturally relevant health promotion. When working with families that use the path of least resistance approach, public health professionals can promote time-saving cooking techniques such as prepping ingredients ahead or freezing leftover food for another day. In addition, when working with families with children described as pickyeaters, public health professionals can encourage age-appropriate interventions that promote healthy eating among children and adolescents. These include increased exposure to a variety of foods at an early age, increased family meal times, and increased participation in cooking and meal preparation (Campbell, Crawford, Salmon, Carver, Garnett \& Baur, 2007; Sen, Carpenter, Hochstadt, Huddleson, Kustanovich, Reynolds, \& Roberts, 2012; Hersch, Perdue, Ambroz, \& Boucher, 2014).

\section{Acknowledgements}

This research was supported by the American Association of University Women Dissertation Year Fellowship 2013-2014 while the corresponding author was a doctoral student at the University of California, Los Angeles.

\section{References}

Abraído-Lanza, A. F., Armbrister, A. N., Flórez, K. R., \& Aguirre, A. N. (2006). Toward a theory-driven model of acculturation in public health research. American Journal of Public Health, 96, 13421346.

Ayala, G. X., Baquero, B., \& Klinger, S. (2008). A systematic review of the relationship between acculturation and diet among Latinos in the United States: Implications for future research. Journal of the American Dietetic Association, 108, 1330-1344.

Batis, C., Hernandez-Barrera, L., Barquera, S., Rivera, J.A., \& Popkin, B. (2011). Food acculturation drives dietary differences among Mexicans, Mexican Americans, and Non-Hispanic Whites. The Journal of Nutrition, 141(10), 1898-1901.

Berg, B.L. (2001). Qualitative Research Methods for the Social Sciences. 4th ed. Boston, MA: Allyn and Bacon.

Blake, C., \& Bisogni, C. (2003). Personal and family food choice schemas of rural women in Upstate New York. Journal of Nutrition Education \& Behavior; 35, 282-293.

Blake, C. E., Wethington, E., Farrell, T. J., Bisogni, C. A., \& Devine, C. M. (2011). Behavioral contexts, food-choice coping strategies, and dietary quality of a multiethnic sample of employed parents. Journal of the American Dietetic Association, 111(3), 401-407.

Bowen, R. L., \& Devine, C. M. (2011). "Watching a person who knows how to cook, you'll learn a lot." Linked lives, cultural transmission, and the food choices of Puerto Rican girls. Appetite, 56, 290298.

Campbell, K. J., Crawford, D. A., Salmon, J., Carver, A., Garnett, S. P., \& Baur, L. A. (2007). Associations between the home food environment and obesity-promoting eating behaviors in adolescence. Obesity, 15, 719-730. doi:10.1038/oby.2007.553

Carruth, B. R, \& Skinner, J. D. (2000). Revisiting the picky eater phenomenon. Neophobic behaviors of young children. Journal of the American College of Nutrition, 19(6), 771-780. 
Carruth, B. R, \& Ziegler, P. J., Gordon, A., \& Barr, S. I. (2004). Prevalence of picky eaters among infants and toddlers and their caregivers' decisions about offering a new food. Journal of the American Dietetic Association, 104, 57-64.

Charmaz, K. (2006). Constructing grounded theory: A practical guide through qualitative analysis. London; Thousand Oaks, CA: Sage Publications.

Devine, C.M. (2005). A life course perspective: understanding food choices in time, social location, and history. Journal of Nutrition Education \& Behavior. May-Jun;37(3):121-8.

Duran, N., Sawyer, M.T., and Luna, K. (2018). Latino adolescents in flux: How do family food decisions impact diet quality? Presented at the $146^{\text {th }}$ American Public Health Association Annual San Diego, CA.

Emerson, R.M. (2001). Contemporary Field Research: Perspectives and Formulations. 2nd ed. Prospect Heights, IL.: Waveland Press.

Furst, T., Connors, M., Bisogni, C.A., Sobal, J., and Falk, L.W. (1996). A conceptual model of the food choice process. Appetite; 26(3):247-265

Gomel, J.N, \& Zamora, A. (2007). English- and Spanish-speaking Latina mothers' beliefs about food, health, and mothering. Journal of Immigrant \& Minority Health, 9, 359-367.

Hersch, D., Perdue, L., Ambroz, T., \& Boucher, J.L. (2014). The impact of cooking classes on foodrelated preferences, attitudes, and behaviors of school-aged children: A Systematic Review of the Evidence, 2003-2014. Preventing Chronic Disease, 11, 140267. doi: http://dx.doi.org/10.5888/pcd11.140267

Kerber, C., Kessler, L. A., Wallace, S. P., \& Burns-Whitmore, B. (2014). Cultural and dietary factors influencing traditional Latino meal patterns: Findings from a focus group discussion. California Journal of Health Promotion, 12, 42-54.

Kirk, M. C., \& Gillespie, A. H. (1990). Factors affecting food choices of working mothers with young families. Journal of Nutrition Education, 22,161-168.

Lara, M., Gamboa, M., Kahramanian, M.I., Morales, L.S., \& Hayes Bautista, D.E. (2005). Acculturation and Latino health in the United States: A review of the literature. Annual Review of Public Health, 26, 367-397.

Lindsay, A. C., Sussner, K. M., Greaney, M. L., \& Peterson, K. E. (2009). Influence of social context on eating, physical activity, and sedentary behaviors of Latina mothers and their preschool-age children. Health Education \& Behavior: The Official Publication of the Society for Public Health Education, 36(1), 81-96.

Mazur, R. E., Marquis, G. S., \& Jensen, H. H. (2003). Diet and food insufficiency among Hispanic youths: Acculturation and socioeconomic factors in the third National Health and Nutrition Examination Survey. American Journal of Clinical Nutrition, 78(6), 1120-1127.

Sawyer, M. T. (2015). Food decisions among working Latino families in California (Order No. 3703675). Available from ProQuest Dissertations \& Theses Global: The Humanities and Social Sciences Collection. (1689442262).

Sawyer, M.T., Duran, N., Luna, K. (2018). Latino adolescent and parent communication patterns and family food decisions: How does talking about food relate to more healthful diets? Presented at the $146^{\text {th }}$ American Public Health Association Annual San Diego, CA.

Sen, S., Carpenter, A., Hochstadt, J., Huddleson, J. Y., Kustanovich, V., Reynolds, A. A., \& Roberts, S. (2012). Nutrition, weight gain and eating behavior in pregnancy: A review of experimental evidence for long-term effects on the risk of obesity in offspring. Physiology \& Behavior, 107(1), 138-145.

Slusser ,W. M., Prelip, M., Kinsler, J., Toller Erasquin, J., Thai, C., \& Neumann, C. G. (2011). Challenges to parent nutrition education: A qualitative study of parents of urban children attending low-income schools. Public Health Nutrition; 14(10), 1833-1841.

Slusser, W. M., Toller Erasquin, J., Prelip, M., Fischer, H., Cumberland, W. G., Frankel, F., \& Neumann, C. (2012). Nutrition knowledge and behaviours of low-income Latino parents of preschoolers: 
Assocations with nutrition-related parenting practices. Early Child Development and Care, 182, 1041-1055.

Sobal J, Bisogni CA. Constructing food choice decisions. Annals of Behavioral Medicine. 2009;38 (Supplement 1):S37-S46;

Sussner, K. M, Lindsay, A. C., Greaney, M. L., \& Peterson, K. E. (2008). The influence of immigrant status and acculturation on the development of overweight in Latino families: A qualitative study. Journal of Immigrant and Minority Health / Center for Minority Public Health, 10(6), 497-505.

Turner, B. J., Navuluri, N., Winkler, P., Vale, S., \& Finley, E. (2014). A qualitative study of family healthy lifestyle behaviors of Mexican-American and Mexican immigrant fathers and mothers. Journal of the Academy of Nutrition and Dietetics, 114, 562-569.

Author Information

Mirna Troncoso Sawyer, PhD, MPH

CSUN, Department of Health Sciences

Mail Code 8285

Northridge CA 91330

Office 818-677-7610

Fax 818-677-2045

Emailmirna.sawyer@csun.edu 